\title{
Identidade de gênero, sexualidade e intervenções terapêuticas em A garota dinamarquesa (2015)
}

\author{
Gender identity, sexuality, and therapeutic \\ interventions in The danish girl (2015)
}

\author{
Eliza Teixeira de Toledo \\ Pós-graduação em História das Ciências e da Saúde/Fundação Oswaldo Cruz. \\ elizattoledo@gmail.com
}

Isabela de Oliveira Dornelas

Faculdade de Filosofia e Ciências Humanas Grupo Scientia/Universidade Federal de Minas Gerais. isadornelas@gmail.com

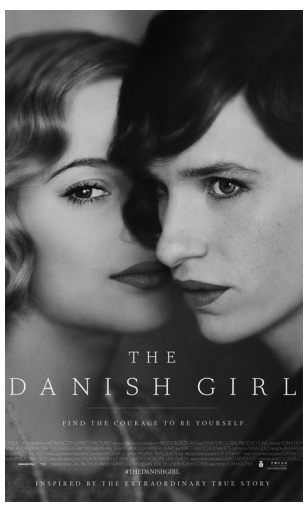

The Danish girl. Direção: Tom Hooper. EUA, Reino Unido, Alemanha. 1h59min. 2015.
Dara Lili Elbe, ${ }^{1}$ nascida Einar Wegener e personagem principal do 1 longa A garota dinamarquesa (The Danish Girl, 2015), dirigido por Tom Hooper, sentir-se mulher foi o essencial para iniciar o incômodo que ela categorizava como discordância entre sua mente e seu corpo. O filme, por meio de uma cadência suave, desenrola o processo de transição entre o promissor talento das artes, Einer, e a tímida Lili Elbe.

Baseada no diário de Lili - originalmente publicado em 1933 com o título Man into woman -, a produção cinematográfica revela que processos patologizantes foram a resposta de diferentes campos da medicina para sua identidade de gênero. A crença na medicina como um campo que possibilitaria alívio para seus sofrimentos levou Lili e sua companheira, a artista plástica Gerda Wegener, a procurar seus recursos terapêuticos.

O filme narra que as visitas de Lili a especialistas em Copenhagen resultaram, a princípio, na prescrição do uso de radiação em sua região genital, com o fim de readequá-la a sua condição biológica. O médico que trata Lili reforça sua confiabilidade ao afirmar: "Sou um especialista." Sua explicação para as dores, o "estado confuso de masculinidade" e a "infertilidade" de Lili - pressuposta por ela e Gerda não terem tido filhos - era a de que seriam provocados por um desequilíbrio químico. O tratamento por radiologia rende ao filme a primeira de muitas cenas que ainda se seguirão ambientadas em consultórios médicos: debilitada ao fim do procedimento, a personagem diz a seu médico: "Você machucou Lili." 
A constatação de que a terapêutica não teria alcançado o objetivo desejado faz com que a conclusão do médico sobre o estado patológico de Lili se modifique. Por não se reconhecer como Einer e não viver segundo padrões do gênero masculino, ela é diagnosticada com perversão e intimada a comparecer ao Hospital Psiquiátrico de Sankt Hans para tratamento. O termo perversão, segundo a ordem médica no final do século XIX e no século XX, passou a ser usado em relação aos comportamentos sexuais que fugiam à norma que identificava a sexualidade sadia à fecundação (Salles, Ceccarelli, 2010). Mais do que isso, a identidade de gênero feminino de Lili pressupõe, para os médicos, um desvio no âmbito da sexualidade, em clara confusão corrente no começo daquele século entre identidade de gênero e orientação sexual (Butler, 2009).

Em Paris, para onde a dupla se muda para acompanhar a efervescente cena artística do começo dos anos 1930, uma figura do passado de Lili retorna a sua vida: Hans Axgil. Hans, no intuito de auxiliar seu amigo de infância que vivencia pensamentos de suicídio e momentos de violência por não se adequar ao gênero de Einer, propõe que busquem novamente ajuda médica, reafirmando a legitimação social da medicina naquele contexto. Em um consultório em meio a imagens de crânios e cérebros, um dos médicos atesta que a personagem passa por um "estado de confusão mental" e propõe outra terapia somática. Os "pequenos furos" que seriam feitos no crânio da paciente nos remetem à psicocirurgia, utilizada na primeira metade do século XX contra, entre outros, sintomas de cunho "desviante" em relação à sexualidade e ao gênero² (Braslow, 1997; Pressman, 1998; Perreault, 2011, 2012).

Durante uma sessão de psicanálise, um novo especialista constata que sua paciente é homossexual. Essa cena nos remete ao trabalho de Michel Foucault (1978), para quem, na era moderna, a homossexualidade toma lugar "entre as estratificações da loucura". Em visita a outro médico, o relato da paciente sobre seu mal-estar - motivado pela exigência de corresponder ao modelo de normalidade de gênero - leva à nova classificação: esquizofrenia.

Amparada por Gerda, que afirma que a companheira não é louca e procura ainda ajuda nas ciências biomédicas, Lili conhece o médico alemão Kurt Warnekros, que propõe a cirurgia de redesignação sexual associada ao uso de hormônios. Esse médico a alerta sobre o altíssimo risco do procedimento, nunca antes tentado, que consistia na reconstrução dos genitais, o implante de útero e de ovários.

Interessa-nos aqui balizar tais intervenções terapêuticas em seu contexto histórico levantando a seguinte pergunta: o que é ser mulher naquela conjuntura? Para Fabíola Rohden (2008), no começo do século XX os hormônios ganham centralidade na consolidação do modelo dos dois sexos. O enxerto dos ovários pretendido por Warnakros é consonante a uma concepção hormonal de "natureza feminina", pois desse órgão parte a regulação dos hormônios, substâncias que determinariam os comportamentos de gênero adequados ao corpo biológico. A tentativa de implantação de um útero no corpo de Lili Elbe e as tomadas que demonstram o desejo de ser mãe conectam-se também à esteira de progressiva valorização da maternidade presenciada pelo Ocidente desde o século XVIII (Badinter, 1985). A ideia de maternidade como destino biológico das mulheres, consolidada na década de 1930, influencia fortemente a escolha de Lili pelas operações. Com o intuito de se sentir "uma mulher completa", aquela que carrega em seu corpo os atributos necessários para ser mãe, 
a personagem confia seu corpo a invasivas e complexas técnicas a fim de tornar-se apta a desempenhar esse papel.

Lili morre em decorrência de complicações de sua última cirurgia de transplante de ovários e útero. O desconforto de gênero que ela sentia motivou seu anseio em se adequar anatômica e biologicamente ao modelo que lhe permitiria viver em plenitude sua feminilidade. O filme nos provoca, assim, a reflexão sobre demandas sociais de adequação de gênero ao sexo biológico promovidas também pelas ciências biomédicas. Tais demandas fizeram com que Lili, assim como diversos outros indivíduos, fosse patologizada e interiorizasse tais patologias segundo o sentimento de não adaptação entre corpo sexuado e gênero - e que por esse motivo passasse por diversas intervenções terapêuticas. Em meio a cenas de profunda sensibilidade, a produção nos estimula a pensar as bases socioculturais da construção do conhecimento científico segundo um modelo binário de gênero.

Com suas limitações - como ser protagonizado por um ator cisgênero, o que cabe ser problematizado -, A garota dinamarquesa dá visibilidade a debates atuais sobre relações de gênero por meio da história da primeira paciente registrada a passar pela cirurgia de redesignação sexual. Não por acaso, assim como no contexto de acirradas discussões de gênero na década de 1950 - quando o diário de Lili foi reeditado -, o longa foi agora produzido. Podemos conceber que a adaptação da história para o filme está inserida em um contexto de intensas demandas por reconhecimento de direitos civis por parte de indivíduos transgêneros e transexuais. Mais do que isso, algumas de suas cenas nos levam a pensar sobre o dualismo hierárquico de gênero que vivemos atualmente. Assim, o filme é um aporte para o debate sobre tais temáticas, para novos questionamentos e permite olhares diversos, segundo vivências diversas, para seu enredo.

\section{NOTAS}

\footnotetext{
${ }^{1}$ Fizemos a opção por tratar a personagem somente por Lili Elbe em respeito a sua identidade de gênero.

${ }^{2} \mathrm{O}$ desenvolvimento da terapêutica é legado ao neurologista português Egas Moniz, em 1936; contudo, desde finais do século XIX, o neuropsiquiatra suíço Gottlieb Burckhardt experimentou a remoção de algumas seções do cérebro em casos de esquizofrenia crônica (Collins, Stam, 2014).
}

\section{REFERÊNCIAS}

BADINTER, Elisabeth.

Um amor conquistado: o mito do amor materno. Rio de Janeiro: Nova Fronteira. 1985.

BRASLOW, Joel.

Mental ills and bodily cures: psychiatric treatment in the first half of the twentieth century.

Berkeley: University of California Press. 1997.

BUTLER, Judith.

Desdiagnosticando o gênero. Physis, v.19, n.1, p.95-126. 2009.

COLLINS, Brianne M.; STAM, J. Henderikus. A transnational perspective on psychosurgery: beyond Portugal and the United States. Jounal of the Histrory of the Neurosciences, v.23, n.4, p.335-334. 2014.

FOUCAULT, Michel.

A história da loucura. São Paulo: Perspectiva. 1978.

PERREAULT, Isabelle.

Esprits troublés et corps déviants: les fonctions de la psychochirurgie à Saint-Jean-de-Dieu, 19481956. In: Frigon, Sylvie (Ed.). Corps suspect, corps déviant. Montréal: Éditions du Remue-ménage. p.205-227. 2012.

PERREAULT, Isabelle.

Psychochirurgie et homosexualité: quelques cas 
à l'Hôpital Saint-Jean-de-Dieu à la mi-XXe siècle. In: Corriveau, P.; Daoust, V. (Ed.). La régulation sociale des minorités sexuelles: l'inquiétude de la difference. Québec: Presses de l'Université du Québec. p.27-44. 2011.

PRESSMAN, Jack.

Last resort: psychosurgery and the limits of medicine. Cambridge: Cambridge University Press. 1998.
ROHDEN, Fabíola.

O império dos hormônios e a construção da diferença entre os sexos. História, Ciências, Saúde - Manguinhos, v.15, supl., p.133-152. 2008.

SALLES, Ana Cristina Teixeira da Costa; CECCARELLI, Paulo Roberto.

A invenção da sexualidade, Reverso, ano 32, n.60, p.15-24. 2010.

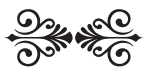




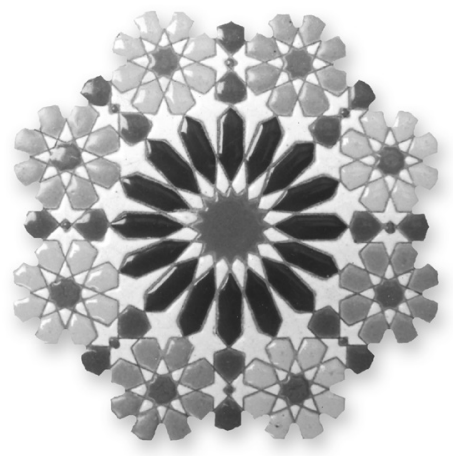

